\title{
Inovação, Governança e Desenvolvimento Sustentável em Destinos Turísticos Inteligentes: o caso de Belo Horizonte/MG, Brasil
}

\author{
Daniela, Rocco \\ Grupo Única Educacional, Brasil \\ Núcleo de Pós-graduação e Pesquisa (NPP) \\ danielarocco@ymail.com \\ Daniela, Alvares \\ Instituto Federal de Minas Gerais, Brasil \\ Pró-reitoria de Extensão \\ danifantoni@hotmail.com
}

\section{Resumo}

O objetivo deste artigo foi analisar iniciativas inovadoras realizadas em consonância com o desenvolvimento sustentável e com estímulo à governança, inseridas no contexto de um potencial destino turístico inteligente (DTI), a saber, Belo Horizonte, localizado no estado de Minas Gerais, Brasil. Esta pesquisa, que foi desenvolvida entre janeiro e maio de 2017, é de natureza exploratória e caráter qualitativo. Foram entrevistados representantes de cinco instituições com as seguintes atuações: gestão pública - Secretaria Estadual de Turismo de Minas Gerais (Setur/MG) e Empresa Municipal de Turismo (Belotur); parceria público-privada - Parque Tecnológico de Belo Horizonte (BH-TEC), startup - Experience Infinity e coletivo urbano - Beagá Cool. Os resultados da pesquisa indicaram uma capacidade inovadora e criativa na capital mineira, bem como um potencial destino turístico inteligente. Isto porque as iniciativas inovadoras/criativas na cidade ainda são pontuais e o estágio de inovação, conforme os cinco entrevistados, ainda se encontra na fase inicial.

Palavras-chave: Inovação, Governança, Desenvolvimento Sustentável, Destinos Turísticos Inteligentes 
Actas del Seminario Internacional Destinos Turísticos Inteligentes:

nuevos horizontes en la investigación y gestión del turismo

Universidad de Alicante, 26 y 27 de octubre de 2017

\begin{abstract}
The aim of this paper was to analyze innovative initiatives carried out in line with sustainable development and with a stimulus to governance, inserted in the context of a potential intelligent tourist destination (DTI), namely Belo Horizonte, located in the state of Minas Gerais, Brazil. This research, which was developed between January and May 2017, is exploratory and qualitative. Representatives of five institutions were interviewed: public management - State Secretariat of Tourism of Minas Gerais (Setur / MG) and Municipal Tourism Company (Belotur); Public-private partnership - Belo Horizonte Technology Park (BH-TEC), startup - Infinity Experience and urban collective - Beagá Cool. The results of the survey indicated an innovative and creative capacity in the capital of Minas Gerais, as well as a potential tourist destination. This is because the innovative / creative initiatives in the city are still punctual and the stage of innovation, according to the five interviewees, is still in the initial phase.
\end{abstract}

Keywords: Innovation, Governance, Sustainable Development, Smart Tourism Destinations

\title{
1. Introdução
}

Este artigo teve como objetivo analisar iniciativas inovadoras realizadas em consonância com o desenvolvimento sustentável e com estímulo à governança, inseridas no contexto de um potencial destino turístico inteligente (DTI). Segundo a Sociedade Mercantil Estatal para a Gestão da Inovação e das Tecnologias Turísticas, uma das maiores referências nessa área, um DTI é um destino turístico inovador baseado essencialmente em infraestrutura de tecnologia, gerando, assim, desenvolvimento sustentável de forma integrada, qualidade de vida para residentes e qualidade da experiência para os visitantes em áreas turísticas (Segittur, 2012; Lopez de Avila, 2015).

Atualmente, três bilhões de pessoas no mundo inteiro estão conectadas à Internet, reflexo de uma sociedade cada vez mais hiperconectada (Blanco, 2015). Consequentemente, acostumadas com as facilidades propiciadas por meio das novas tecnologias, essa grande quantidade de pessoas tende a exigir que os serviços públicos, assim como os bens/serviços gerados pela iniciativa privada, também possam ser produzidos e consumidos de forma inteligente. No caso do turismo, de acordo com especialistas em comportamento do consumidor, existe um novo perfil do turista, chamado de «consumidor i», por serem: inteligentes, inflexíveis, informados e impulsivos 
Actas del Seminario Internacional Destinos Turísticos Inteligentes:

nuevos horizontes en la investigación y gestión del turismo

Universidad de Alicante, 26 y 27 de octubre de 2017

(CLARÍN, 2011). Diante desse novo consumidor, há a necessidade de se quebrar paradigmas arraigados, mas que já não servem para explicar mudanças de comportamento, além de ser imprescindível atuar nas áreas pública e privada no intuito de se atender a essas novas demandas.

O campo empírico desta pesquisa foi desenvolvido em Belo Horizonte, capital do estado de Minas Gerais - Brasil, com destaque para as instituições públicas, parceria público-privada, startup e coletivo urbano. Este último pode ser definido como: grupos independentes que geralmente se reúnem voluntariamente em cidades com o objetivo principal de criação coletiva, tanto para a fotografia, arte, cinema, teatro, música, entre outras criações e manifestações culturais, sendo que este é um conceito ainda novo e pouco aprofundado na literatura (Alvares \& Carneiro, 2014).

Belo Horizonte foi a primeira cidade moderna planejada do país, sendo inaugurada em 1897 (Belo Horizonte, 2014), e embora tenha sido projetada nos limites da Avenida do Contorno, nas últimas décadas se expandiu em termos físicos e digitais. Destaca-se que no Brasil já existem projetos de implementação de cidades digitais, e ainda que Belo Horizonte não seja assim considerada oficialmente, tem grande potencial. Ademais, observa-se que na cidade houve mudanças - relacionadas à governança, ao desenvolvimento sustentável e à inovação -, cujo contexto representa um movimento efervescente de estímulo à criatividade e à inovação, como poderá ser percebido por meio dos resultados dessa pesquisa.

É importante ressaltar, segundo Arbix (2007), que o debate sobre inovação no Brasil está em sua "primeira infância», embora haja futuro favorável para o desenvolvimento de produtos inovadores. Neste sentido, a proposta deste artigo se configura como uma forma de contribuir para o fortalecimento de investigações sobre os temas: inovação, governança e desenvolvimento sustentável, que encontram terreno fértil, inclusive, para o aprofundamento teórico sobre DTI.

Neste âmbito, o presente estudo realiza, inicialmente, reflexão sobre "cidades inteligentes», "destinos turísticos inteligentes», «inovação», "governança» e «desenvolvimento sustentável». Na sequência, são estabelecidos os métodos adotados para a consecução dos objetivos delineados e, por fim, são apresentados os resultados da pesquisa de forma crítico-analítica. 
Actas del Seminario Internacional Destinos Turísticos Inteligentes:

nuevos horizontes en la investigación y gestión del turismo

Universidad de Alicante, 26 y 27 de octubre de 2017

\section{Cidades inteligentes: a gênese do conceito de destinos turísticos inteligentes}

Segundo previsões da Organização das Nações Unidas (ONU), cerca de 60\% da população mundial residirá nas cidades até 2030 (United Nations, 2014). Neste cenário, é importante ressaltar que as áreas urbanas nos dias atuais concentram, em grande parte, desafios de ordem política, econômica, social, ambiental e territorial. Fatos estes que requerem de maneira premente: (i) ações sustentáveis; (ii) incremento de instâncias de governança e (iii) estímulo ao desenvolvimento de inovações. Por sua vez, demandam estratégias integradas, cujas alternativas e soluções têm sido frequentemente encontradas nas ditas "cidades inteligentes» ou smart cities.

O conceito de smart cities se originou na década de 1990, a partir do contexto de "crescimento inteligente», sobretudo com o advento da Internet e das «cidades digitais» (Bollier, 1998; Lemos, 2013). Hoje está vinculado ao uso integrado de Tecnologias da Informação e Comunicação (TICS) para o bem-estar coletivo da população urbana, com destaque para melhorias sistêmicas em termos de comunicação, mobilidade, transporte, saúde, segurança, tratamento dos resíduos, entre outros. Essas melhorias, segundo Brandão, Joia e Teles (2016), são ativadas por meio de sistemas hiperconectados, dispositivos, sensores e atuadores inteligentes, estações de trabalho computadorizadas e constantes processos de monitoramento produzidos pelos próprios computadores, gerando, inclusive, dados e informações em tempo real. Tem-se ainda neste contexto, o uso intensivo da nuvem computadorizada e da Internet das coisas (IoT - Internet of things), que são capazes de gerar ainda mais eficiência e efetividade nos processos produtivos e dinâmicas sociais. Tudo isso corresponde à dita «Indústria 4.0», pautada na quarta revolução industrial, na qual há uma interface profunda entre o mundo real e virtual, o que tende a desencadear, cada vez mais, revoluções digitais (FDC, 2016; Schwab, 2017).

De acordo com o IESE, Cities in Motion Index (2016), as cinco cidades mais inteligentes do mundo, em relação a 181 cidades analisadas, são Nova York (EUA), Londres (Reino Unido), Paris (França), São Francisco (EUA) e Boston (EUA). Este estudo foi desenvolvido com base em 77 indicadores, distribuídos por sua vez em 10 dimensões: 1 . economia; 2 . capital humano (capacidade de atrair talentos); 3 . tecnologia; 4. meio ambiente; 5 . alcance internacional (turismo); 6. coesão social; 7. mobilidade e transporte; 8. 
Actas del Seminario Internacional Destinos Turísticos Inteligentes:

nuevos horizontes en la investigación y gestión del turismo

Universidad de Alicante, 26 y 27 de octubre de 2017

governança; 9. planejamento urbano e 10. gestão pública. Essas dimensões estão correlacionadas em um contexto de sustentabilidade, conectividade, inovação e coesão social, que por sua vez possuem requisitos básicos ${ }^{1}$ para se criar condições de prosperidade na cidade, tal como mostra a Figura 1 a seguir:

Figura 1: Modelo Proposto para Criar Condições de Prosperidade na Cidade

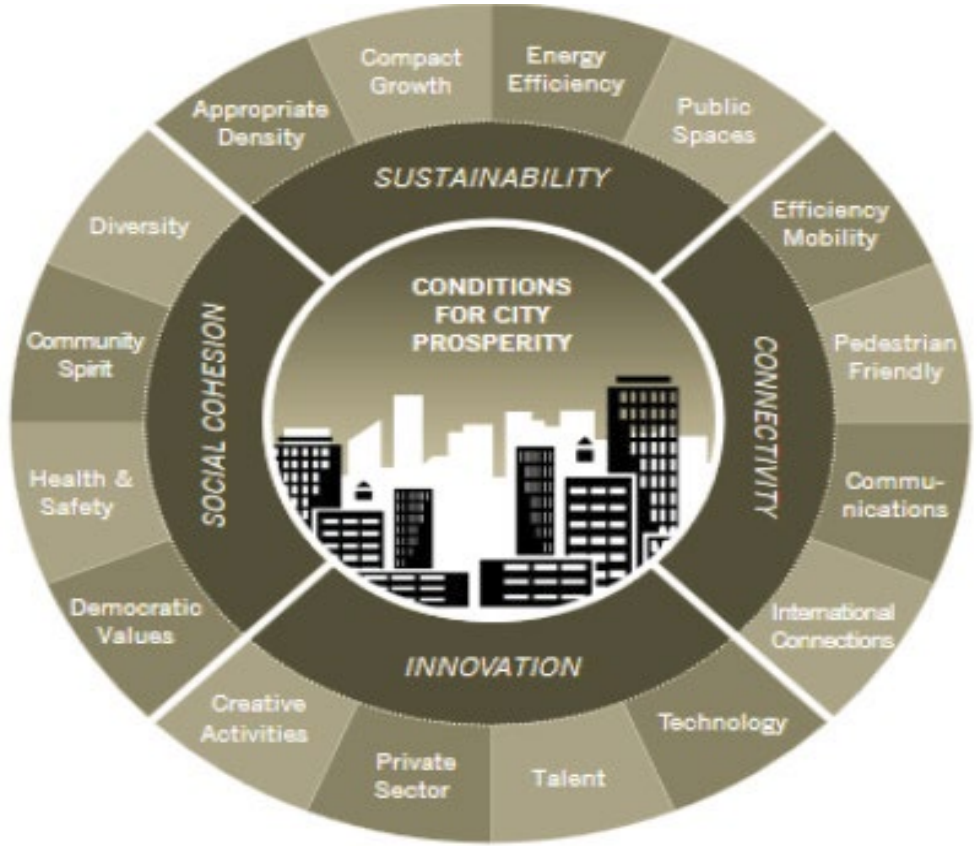

Fonte: IESE (2016)

As experiências mais exitosas de cidades inteligentes têm sido destacadas na Europa e Ásia (Blanco, 2015; Brandão; Joia \& Teles, 2016; IESE; 2016), e são particularmente nesses continentes que há o maior fluxo de

1. Os requisitos básicos contidos na Figura 1 são: Eficiência energética, espaços públicos, mobilidade eficiente, facilidades para pedestres, comunicações, conexões internacionais, tecnologia, talentos, iniciativa privada, atividades criativas, valores democráticos, saúde e segurança, espírito de comunidade, diversidade, densidade adequada e crescimento compacto (IESE, 2016). 
Actas del Seminario Internacional Destinos Turísticos Inteligentes:

nuevos horizontes en la investigación y gestión del turismo

Universidad de Alicante, 26 y 27 de octubre de 2017

turismo (OMT, 2016). No continente europeu, Londres, Paris e Amsterdam se destacam como cidades inteligentes, e na Ásia as cidades de Seul, Tóquio e Singapura são consideradas como mais inteligentes (IESE, 2016). A Espanha é emblemática pelo incentivo de cidades inteligentes na Europa, a exemplo de Barcelona, Madrid e Valência. Embora Santander (cidade espanhola) não tenha sido considerada no IESE Cities in Motion Index 2016, possui um projeto pioneiro chamado "SmartSantander», que objetiva ser a primeira cidade do mundo 100\% inteligente (SmartSantander, 2017). Quanto ao continente asiático, além do crescimento anual de chegadas de turistas internacionais e entradas de divisas (OMT, 2016), países como Coreia, Japão e China, além dos anteriormente citados, têm sido os maiores expoentes em termos de criação e desenvolvimento de cidades inteligentes (IESE, 2016). Não obstante, os referidos países têm em comum o crescimento do fluxo turístico e ações relacionadas ao conceito de Destino Turístico Inteligente (DTI) associadas, ao mesmo tempo, às cidades inteligentes.

É importante explicitar que todo DTI é uma cidade inteligente, mas nem toda cidade inteligente é um DTI. Isto porque nem toda cidade inteligente possui estruturas de comunicação e inteligência voltadas para atender, especificamente, às demandas turísticas. Por outro lado, um DTI obviamente se apropria dos mesmos recursos e serviços de uma cidade inteligente, como transporte público, mobilidade, saúde, segurança, entre outros (Brandão; Joia \& Teles, 2016).

De acordo com Cohen (2012), para se desenvolver cidades inteligentes há seis dimensões a serem consideradas: (i) smart people, (ii) smart mobility, (iii) smart living, (iv) smart environment, (v) smart government e (vi) smart economy. Essas "dimensões inteligentes», associadas às questões sociais, de mobilidade, estilo de vida, meio ambiente, governança e economia, podem ser aplicadas também aos DTI, conforme estabelecido pelos autores Buhalis e Amaranggana (2014).

Pode-se afirmar que, embora o conceito de DTI venha sido abordado desde 2012 (Sebrae, 2016), ainda se constata uma imprecisão conceitual (Li et al., 2017). Trazer inteligência aos destinos turísticos requer interconectar de maneira dinâmica os atores sociais por meio de plataforma tecnológica, na qual as informações relacionadas às atividades turísticas possam ser trocadas instantaneamente. E ainda, essa plataforma pode apoiar a criação e facilitação de experiências de turismo em tempo real (Buhalis \& Amaranggana, 2014). Ressalta-se que a tecnologia é citada por esses autores (2014) 
Actas del Seminario Internacional Destinos Turísticos Inteligentes: nuevos horizontes en la investigación y gestión del turismo

Universidad de Alicante, 26 y 27 de octubre de 2017

como algo primordial para os DTI. Por outro lado, Gretzel et al. (2015) alertam que as tecnologias são importantes para os DTI, mas não são suficientes para definir tudo o que está inserido nesse universo.

De acordo com o Sebrae (2016),

Os destinos turísticos inteligentes são estruturas turísticas diferenciadas que facilitam a interação e integração do visitante, antes, durante e depois da viagem, e incrementam a qualidade de sua experiência com o destino, por meio do uso de metodologias e tecnologias inovadoras.

Ressalta-se que o Sebrae (2016) pontua algo relevante, a saber, metodologias inovadoras e não somente tecnologias. Além disso, explicita a questão da estrutura turística diferenciada, na qual enfatiza-se: «o novo» e «o fora do comum", que pode ser advindo de uma inovação, e aqui acrescenta-se que esta pode ser: (i) inovação disruptiva/radical (gera destruição criativa de produtos vigentes, provocando profundas mudanças no mercado e sociedade), (ii) incremental (melhorias que incrementam o bem/serviço, quer seja por meio de uma adaptação, refinamento ou aperfeiçoamento em relação a um produto pré-estabelecido) e/ou (iii) aberta (rede aberta que conecta diversos stakeholders em um processo de inovação incremental e/ou radical) (Arbix, 2007; Tidd \& Bessant, 2015).

Um destino turístico para ser qualificado como «inteligente» deve propiciar facilidades não apenas para turistas e excursionistas, como também para os residentes. Pensar em cidade inteligente e em DTI é (i) considerar o bem-estar das pessoas; (ii) propor soluções inovadoras e sustentáveis para problemas existentes; (iii) detectar oportunidades de negócios (bens/serviços), considerando os preceitos da sustentabilidade; (iv) fortalecer redes ${ }^{2}$,

2. "A sociedade em rede, em termos simples, é uma estrutura social baseada em redes operadas por tecnologias de comunicação e informação fundamentadas na microelectrónica (sic) e em redes digitais de computadores que geram, processam e distribuem informação a partir de conhecimento acumulado nos nós dessas redes. A rede é a estrutura formal (vide Monge e Contractor, 2004). É um sistema de nós interligados. E os nós são, em linguagem formal, os pontos onde a curva se intersecta a si própria. As redes são estruturas abertas que evoluem acrescentando ou removendo nós de acordo com as mudanças necessárias dos programas que conseguem atingir os objectivos (sic) de performance para a rede. Estes programas são decididos socialmente fora da rede mas a partir do momento em que são inscritos na lógica da rede, a rede vai seguir eficientemente essas instruções, acrescentando, apagando e reconfigurando, até que um novo programa substitua ou modifique os códigos que comandam esse sistema operativo" (CASTELLS, 2006, p. 20). 
Actas del Seminario Internacional Destinos Turísticos Inteligentes:

nuevos horizontes en la investigación y gestión del turismo

Universidad de Alicante, 26 y 27 de octubre de 2017

formar capital social ${ }^{3}$ e consolidar instâncias de governança e, por fim, (v) utilizar a tecnologia como um meio, e não como finalidade para criação de DTI.

\section{Inovação, governança e desenvolvimento sustentável nos destinos turísticos inteligentes}

De acordo com o Sebrae (2016), os DTI são baseados em três pilares, a saber: tecnologia, governança e desenvolvimento sustentável. No entanto, acredita-se que a tecnologia é uma parte da inovação, conforme referenciado por Gretzel et al. (2015), sendo que a inovação, por sua vez, engloba um processo muito mais amplo e que não necessariamente demanda investimentos altíssimos e soluções tecnológicas (De Bes \& Kotler, 2011; Rocco, 2014).

A inovação é um processo que cria valor para as pessoas e pode ser um produto novo ou melhorado para ser levado ao mercado (OECD, 2005). É um conceito e até mesmo um fenômeno complexo imbuído de dinamismo, busca contínua por vantagens competitivas e por vezes estimulado pela obtenção diferenciada de lucro (IBGE, 2015; Tidd \& Bessant, 2015). Embora um dos pilares de DTI seja a tecnologia, é válido ressaltar que a inovação tecnológica surge na literatura recente como um tipo de inovação, sobretudo porque nem toda inovação se apropria da tecnologia para se constituir e que pode envolver, por exemplo, outros tipos de inovação, como de produto, de serviços, de marketing, de modelo de negócio, inovação social, entre outros (OECD, 2005; Rocco, 2014).

A governança, como segundo pilar de um DTI, é a maneira pela qual se exerce o poder na gestão dos recursos econômicos e sociais de um país para o desenvolvimento (Banco Mundial, 1992). Em relação à essa temática, destaca-se o estabelecido por Alvares (2008), sobre a necessidade de se equacionar o planejamento e a gestão "pelos» e "para» os atores sociais, ou seja, enfatiza a importância da participação ativa de todos os atores envolvidos e que sejam gerados benefícios para estes, a partir da apropriação do processo de desenvolvimento turístico.

3. O termo capital social, assim como seu conceito, surgiu na década de 1980 . Na realidade, não há consenso conceitual, sendo que diferentes autores abordam essa temática, entre estes, Pierre Bourdieu, James Coleman e Robert Putnam. De todo modo, capital social pode estar relacionado com o grau de confiança existente entre os atores sociais de uma sociedade, as normas de comportamento cívico praticadas e o nível de associativismo que caracteriza essa sociedade (Putnam, 1996). 
Actas del Seminario Internacional Destinos Turísticos Inteligentes: nuevos horizontes en la investigación y gestión del turismo

Universidad de Alicante, 26 y 27 de octubre de 2017

Alguns fatores justificam a importância da articulação e participação dos atores sociais nos processos de desenvolvimento local, regional ou nacional, como um meio de se assegurar a eficiência/eficácia, a sustentabilidade, o fortalecimento da competitividade turística e a consolidação de um DTI. Entre estes fatores têm-se: (i) consulta aos órgãos afetados diretamente pelos programas e/ou projetos, durante a concepção, a elaboração, a implementação e a avaliação; (ii) a boa governança e o desenvolvimento participativo, nos quais a transparência das ações públicas permitam a diminuição da corrupção; (iii) formação de capital social, (iv) utilização de mecanismos participativos na elaboração de políticas públicas, e (v) consolidação das identidades regionais (Bandeira, 1999).

Conforme advogam Fontes Filho, Oliveira e Leitão (2009):

[...] cresce, em todo mundo, a tendência da administração pública pela descentralização ou downsizing. A ideia central inicial era buscar maior flexibilidade organizacional com base na menor concentração das responsabilidades estratégias e/ou orçamentárias. Isso implica criação e ampliação interinstitucional da esfera pública para outras instituições/organizações e adoção de novos modelos contratuais e de investimentos.

Essa tendência é explícita também no Brasil, a exemplo do Ministério do Turismo. Desde que foi criado, em 2003, possui estrutura de gestão descentralizada, o que para a época foi considerado como inovação institucional, pela criação do Ministério em si e pela forma de gestão. Se antes a gestão do turismo a partir do nível federal era direcionada aos municípios (municipalização), esse processo se tornou insustentável do ponto de vista econômico e estratégico, pois era segmentado e pouco integrado. Hoje, com os fóruns nacionais dos secretários e dirigentes estaduais, fóruns/conselhos estaduais, conselho nacional de turismo e câmaras temáticas, a gestão turística, descentralizada, está associada também à regionalização, pautada por sua vez no enfoque territorial e institucional (Brasil, 2013).

Por fim, o desenvolvimento sustentável (DS), o terceiro pilar de um DTI, está ligado basicamente à conservação da natureza e da cultura, a prosperidade econômica com inclusão produtiva e equidade social (Sachs, 2002; 2004). O desenvolvimento em si pode ser um caminho para se superar as privações individuais, aumentar as oportunidades e estimular, assim, a liberdade humana (Sen, 2010). No que se refere ao DS propriamente dito, este é um conceito que foi chancelado em 1987 por meio da publicação «Nosso Futuro Comum» (Brundtland, 1991), mas cuja gênese, tal como explicitado 
Actas del Seminario Internacional Destinos Turísticos Inteligentes:

nuevos horizontes en la investigación y gestión del turismo

Universidad de Alicante, 26 y 27 de octubre de 2017

por Boff (2012), é datada do ano de 1560. Isto porque foi na Província Saxônia da Alemanha que a palavra nachhaltigkeit (que significa «sustentabilidade») foi usada pela primeira vez para designar a importância de se racionalizar o uso das florestas naquela época. Hoje o DS por vezes é interpretado meramente como um discurso ou um conceito político-normativo, cujo processo de desenvolvimento pode também mascarar a perversidade do sistema capitalista/industrialista (Nascimento, 2012; Boff, 2012). Trata-se de um conceito polissêmico, mas que pode ser entendido como

[...] um processo complexo de desenvolvimento sistêmico, dinâmico, orgânico e integrado que requer valores respaldados na prosperidade econômica, inclusão produtiva, equidade social, conservação da natureza e cultura em um contexto de ética, moral, compromisso, responsabilidade e solidariedade. Estes valores devem ser estimulados entre as atuais e próximas gerações. Além disso, pelo menos as três dimensões (ambiental, social e econômica) devem ser sempre combinadas. A combinação de duas dimensões ou o fortalecimento de apenas uma não é o suficiente para assegurar o desenvolvimento sustentável de uma organização ou território (Rocco, 2014, p. 29).

Perante os argumentos acima debatidos, defende-se que os pilares para um DTI são: (i) inovação; (ii) governança e (iii) desenvolvimento sustentável. Destaca-se que a tecnologia deve ser empregada de forma transversal a estes três pilares, conforme demonstra a Figura 2 abaixo:

Figura 2: Pilares para um DTI

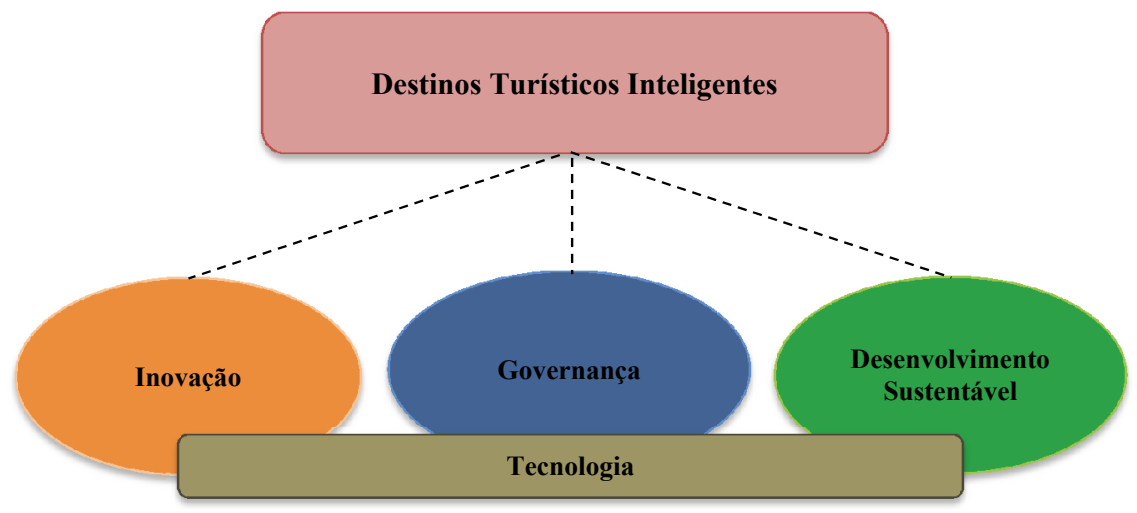

Fonte: Rocco e Alvares (2017), proposta e hipótese de trabalho 
Actas del Seminario Internacional Destinos Turísticos Inteligentes:

nuevos horizontes en la investigación y gestión del turismo

Universidad de Alicante, 26 y 27 de octubre de 2017

Ressalta-se, por fim, que a gestão de um DTI, para ser mais eficiente, eficaz e efetiva, deve considerar, por meio do uso da tecnologia: (i) o tipo e forma de inovação mais adequada à realidade local, (ii) o fomento à governança descentralizada e (iii) o incremento do desenvolvimento sustentável. Estes fatos são importantes, uma vez que o turismo se comporta de forma sistêmica e impacta mais de 50 segmentos na economia (Brasil, 2012), sendo fundamental considerar as dimensões ambiental, social, cultural e econômica. Tudo isso de forma integrada entre os distintos stakeholders do poder público, iniciativa privada, terceiro setor e sociedade civil, o que representa um grande desafio. A seção a seguir apresenta os métodos adotados nesta pesquisa, que vincula essas questões teóricas considerando a possibilidade de Belo Horizonte, campo empírico do estudo, ser ou não um DTI com base na combinação dos pilares inovação, governança e desenvolvimento sustentável.

\section{Métodos}

Esta pesquisa, que foi realizada entre janeiro e maio de 2017, é de natureza exploratória e caráter qualitativo. Como hipótese, propõe-se: para que Belo Horizonte seja considerada um Destino Turístico Inteligente (DTI), é necessário combinar ao mesmo tempo inovação; governança e desenvolvimento sustentável. De modo a mensurar quais são os principais pilares para que Belo Horizonte seja considerada um potencial DTI, este estudo foi desenvolvido em quatro fases, a saber: (i) pesquisa bibliográfica e documental; (ii) elaboração e pré-teste do roteiro de entrevista semiestruturada; (iii) realização de entrevistas e (iv) análise final.

Na primeira fase foram identificadas iniciativas inovadoras e criativas da cidade objeto de estudo, estando essas em consonância com as pautas da governança e do desenvolvimento sustentável. De forma concomitante, na segunda fase, elaborou-se a revisão de literatura e delineou-se o roteiro de entrevista semiestruturada. Põe-se em relevo que esse roteiro foi pré-testado junto a cinco professores universitários com a finalidade de aperfeiçoar o instrumento de coleta de dados e informações. Na terceira fase foram selecionados e entrevistados cinco representantes de instituições que executam e/ou estão implementando iniciativas inovadoras na cidade.

A primeira entrevista foi realizada com uma representante do Parque Tecnológico de Belo Horizonte (BH-TEC), inaugurado em 2012. Trata-se de uma iniciativa público-privada e que hoje mantém 18 empresas residentes, 
Actas del Seminario Internacional Destinos Turísticos Inteligentes:

nuevos horizontes en la investigación y gestión del turismo

Universidad de Alicante, 26 y 27 de octubre de 2017

inseridas, por sua vez, em uma ampla rede inovação, dentre as quais vale mencionar a Universidade Federal de Minas Gerais (UFMG), a Rede de Mineira de Inovação (RMI), a Associação Nacional de Entidades Promotoras de Empreendimentos Inovadores (ANPROTEC) e a International Association of Science Parks and Areas of Innovation (IASP). Ainda em relação ao BH-TEC, destaca-se que este é composto por três centros de tecnologia (CT) da UFMG: CT Vacinas; CT Nanomateriais de Carbono e CT Web.

O segundo entrevistado é um dos idealizadores do Beagá Cool, um coletivo urbano concebido para premiar e divulgar ações e empresas criativas da cidade, estando relacionadas, por exemplo, à alimentação fora do lar; design/editorial; projetos sociais; arte; iniciativas online; ocupação pública e entretenimento. O Beagá Cool foi criado em 2014 e tem como objetivo divulgar as inovações implementadas em Belo Horizonte, assim como mostrar o que há de novo para ser vivenciado e consumido na cidade. Importante esclarecer que essa instituição, além de ser um coletivo urbano, pode ser identificado como um negócio social que atua em formato de rede. Atualmente, o Beagá Cool está implementando um projeto denominado "Distrito Criativo», que pretende propiciar um «novo uso» da cidade e revitalizar um conjunto de lojas no Mercado das Borboletas, localizado no centro de Belo Horizonte.

A terceira entrevista foi com uma das representantes da startup Experience Infinity, sediada em Belo Horizonte, e que atua no setor turístico oferecendo serviços personalizados por meio de uma rede de agentes de viagens. Esta empresa criou, até agora, experiências turísticas em seis estados brasileiros, entre estes Minas Gerais, a partir das seguintes categorias: aventura, cultura, lazer, esporte, gastronomia, religiosa e zen/mística.

O quarto entrevistado é um dos representantes da Secretaria de Estado de Turismo de Minas Gerais (Setur/MG), instituição pública focada no desenvolvimento do turismo. Órgão responsável pela política de turismo no estado, tem como finalidade promover e fomentar ações nessa área, com o objetivo de difundir o potencial turístico do estado, além de gerar emprego e renda e qualidade de vida para as comunidades.

A quinta entrevista foi realizada com um dos representantes da Empresa Municipal de Turismo (Belotur), instituição pública criada para desenvolver o turismo de Belo Horizonte, que tem como missão promover a cidade como polo de atração turística com visibilidade nacional e internacional. Atua para estruturar e divulgar os mais diversos segmentos turísticos, com destaque 
Actas del Seminario Internacional Destinos Turísticos Inteligentes:

nuevos horizontes en la investigación y gestión del turismo

Universidad de Alicante, 26 y 27 de octubre de 2017

para o «turismo de eventos e negócios» e o «turismo cultural». A instituição tem trabalhado em prol do desenvolvimento sustentável e inovador do turismo na cidade, tendo por base o fortalecimento da governança e da cadeia de valor do turismo.

Por fim, a quarta fase da pesquisa diz respeito à análise e discussão, cujo detalhamento dos resultados encontra-se a seguir.

\section{Análise e discussão dos resultados}

\subsection{Belo Horizonte: Inserção no Cenário de Inovação}

A inovação possui grande conexão com a criatividade, que vincula, consequentemente, talento e capacidade inventiva, o que impacta na criação de bens e serviços diferenciados e fortemente marcados pela componente cultural. Inovação e criatividade, cada vez mais, são fatores de competitividade nas economias e, em Belo Horizonte, isso é muito latente.

No Brasil, a economia criativa em 2015 foi responsável por 2,64\% do PIB, a remuneração média da classe criativa é de R\$ 6.270 e são 851.244 profissionais que estão atuando na indústria criativa. Por sua vez, em Minas Gerais a participação estimada em 2015 foi de 1,8\% do PIB, a remuneração média da classe criativa é de R\$ 4.973 e são 74.176 profissionais criativos, estando atrás apenas de São Paulo (327.845 profissionais criativos) e do Rio de Janeiro (99.198 profissionais criativos) (Firjan, 2016).

Particularmente em Belo Horizonte foi criada em 2014 a Casa de Economia Criativa, uma iniciativa do Serviço Brasileiro de Apoio às Micro e Pequenas Empresas e do governo estadual (Sebrae, 2014). O objetivo deste empreendimento é disseminar o setor criativo e gerar cooperação entre empresários desse setor.

Quanto ao turismo, Minas Gerais recebeu em 2016 um total de 26,1 milhões de turistas, introduzindo um valor de $R \$ 17,2$ bilhões na economia mineira. Entre estes turistas, $32,9 \%$ viajaram a lazer. No mesmo ano, a capital mineira recebeu 4,573,952 milhões de turistas, e o gasto total daqueles que vieram a Belo Horizonte foi de R\$2,4 bilhões (Setur, 2017).

Destaca-se que as iniciativas de economia criativa e de inovação no turismo estão em desenvolvimento e é essencial sublinhar que o poder público tem um papel importante nestas mudanças, tomando por base que políticas públicas específicas com foco na inovação e no desenvolvimento sustentável foram estabelecidas, e estão em fase de implementação em 
Actas del Seminario Internacional Destinos Turísticos Inteligentes:

nuevos horizontes en la investigación y gestión del turismo

Universidad de Alicante, 26 y 27 de octubre de 2017

Belo Horizonte. Além do poder público, a iniciativa privada tem papel preponderante, já que sua atuação é baseada na inovação e em projetos que fomentam a economia local com startups e novas empresas. Neste cenário, governança pode ser fortalecida, sobretudo quando as partes interessadas se empoderam da gestão dos recursos na cidade.

No campo do desenvolvimento sustentável, especificamente dos novos negócios (bens/serviços), observa-se que há muitas iniciativas na área da economia criativa, cultura e turismo em Belo Horizonte, tal como pode ser verificado na próxima seção. De todo modo, vale ressaltar que a economia criativa está vinculada desde a criação até a distribuição de produtos constituídos de criatividade, além de grande valor cultural e intelectual. Os setores criativos têm crescido muito e, consequentemente, desenvolvido o que hoje é conhecido como «cidades criativas», resultando em riqueza econômica, social e, sobretudo, cultural (Caiado, 2011, Unctad, 2016). A Figura 3 a seguir apresenta indicadores de cidades inteligentes aplicados em Belo Horizonte, e a coesão social é um dos itens melhor posicionados. Do ponto de vista ambiental, as ações estão abaixo da média em relação a outras cidades estudadas (IESE, 2016).

Figura 3: Cities in Motion Index aplicado a Belo Horizonte

- Belo Horizonte-Brazil

Best

Median

\section{Belo Horizonte-Brazil}

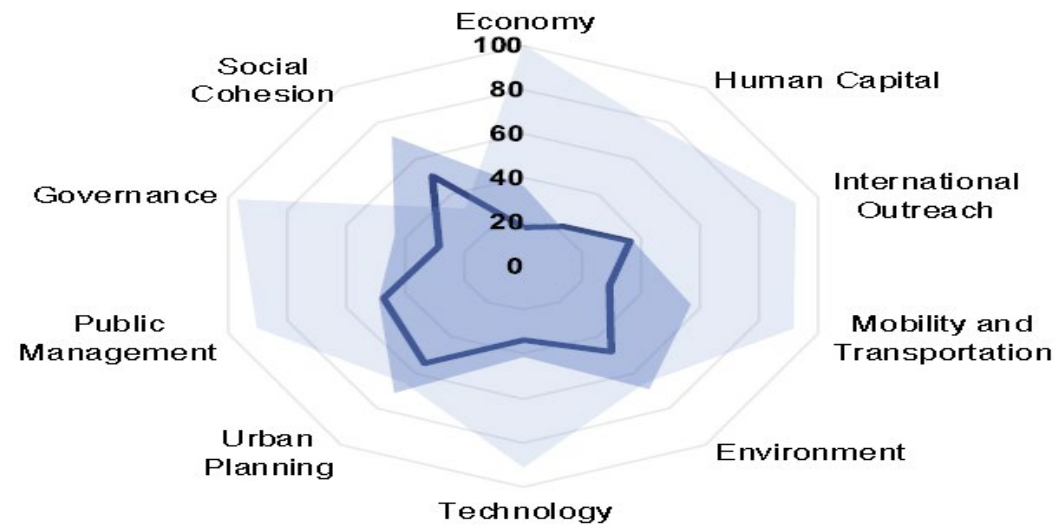

Fonte: IESE (2016) 
Actas del Seminario Internacional Destinos Turísticos Inteligentes:

nuevos horizontes en la investigación y gestión del turismo

Universidad de Alicante, 26 y 27 de octubre de 2017

De acordo com o ranking do Connected Smart Cities, desenvolvido pela Urban Systems a partir de 73 indicadores ${ }^{4}$, as três cidades brasileiras consideradas como mais inteligentes em 2016 foram São Paulo, Rio de Janeiro e Curitiba. Belo Horizonte está na quinta posição, mas em 2015 havia ocupado o terceiro lugar no ranking. Certamente a perda de posição se deve à criação de mais ações inovadoras por parte das outras cidades, de todo modo, vale ressaltar que iniciativas recentes têm sido criadas na capital mineira. Um exemplo é o «InternacionalizaBH», iniciativa desenvolvida pela Associação Comercial e Empresarial de Minas Gerais para fomentar o desenvolvimento dos negócios na cidade no cenário internacional (AC Minas, 2015). Outra iniciativa, lançada oficialmente em maio de 2017, é o Trilha Mineira da Inovação (TMI), que consiste em envolver as principais instituições mineiras para dar suporte ao ecossistema de inovação do estado. Esse envolvimento será materializado, entre outras formas, por meio de um portal online em que serão disponibilizados editais, chamadas, consultorias e linhas de financiamento na área de inovação (TMI, 2017).

\subsection{Resultados e Análise Crítica: Instituições com Atuação em Belo Horizonte}

A partir da pesquisa realizada foi possível levantar um cenário promissor para o desenvolvimento de Belo Horizonte como cidade inteligente, assim como destino turístico inteligente. De acordo com os cinco entrevistados das instituições objeto de análise, Belo Horizonte não pode ser considerada ainda como DTI, mas as ações até então desenvolvidas representam um estágio inicial.

Como pode ser observado no Quadro 1 abaixo, os entrevistados citaram uma série de iniciativas inovadoras criadas e/ou desenvolvidas em Belo Horizonte, assim como algumas iniciativas inovadoras na área de turismo criadas e/ou desenvolvidas em Belo Horizonte.

4. Os indicadores estão vinculados a 11 eixos setoriais, quais sejam: Mobilidade, Urbanismo, Tecnologia e Inovação, Empreendedorismo, Governança, Educação, Energia, Meio Ambiente, Saúde, Segurança e Economia. 


\section{Quadro 1: Iniciativas Inovadores em Belo Horizonte}

\begin{tabular}{|c|c|c|}
\hline INSTITUIÇÕES & $\begin{array}{c}\text { INICIATIVAS INOVADORAS CRIADAS/DESENVOLVIDAS } \\
\text { EM BELO HORIZONTE }\end{array}$ & $\begin{array}{l}\text { INICIATIVAS INOVADORAS NA ÁREA DE } \\
\text { TURISMO CRIADAS/DESENVOLVIDAS EM } \\
\text { BELO HORIZONTE }\end{array}$ \\
\hline $\begin{array}{l}\text { Parque } \\
\text { Tecnológico } \\
\text { de Belo } \\
\text { Horizonte } \\
\text { (BH-TEC) }\end{array}$ & $\begin{array}{l}\text { 1. Duelo de MC's (batalhas musicais com hip hop } \\
\text { que acontecem semanalmente no Viaduto Santa } \\
\text { Tereza). } \\
\text { 2. Eventos em espaços públicos } \\
\text { 3. Espaços de coworking } \\
\text { 4. BH-TEC }\end{array}$ & $\begin{array}{l}\text { 1. Minas international (organização sem fins } \\
\text { lucrativos que visa promover intercâmbio } \\
\text { cultural, inclusive para estrangeiros que } \\
\text { vêm para a cidade, em uma espécie de soft } \\
\text { landing - «aterragem suave»). } \\
\text { 2. Bridge: go care (startup criada em Belo } \\
\text { Horizonte e selecionada na 7.a edição do } \\
\text { Lemonade. Ela conecta agências de viagens } \\
\text { do exterior para que estrangeiros façam } \\
\text { tratamento odontológico na capital mineira } \\
\text { com um valor mais acessível). }\end{array}$ \\
\hline Beagá Cool & $\begin{array}{l}\text { 1. San Pedro Valley (cluster de startups no bairro de } \\
\text { São Pedro, referindo-se ao Silicon Valley, Califórnia, } \\
\text { EUA). } \\
\text { 2. Praia da Estação (evento que ocorre em praça } \\
\text { homônima, cujos participantes, vestidos com roupas } \\
\text { de banho, se refrescam nas fontes e por meio de } \\
\text { água que é jogada com caminhão pipa. Evento que } \\
\text { iniciou como ato político e que hoje se configura } \\
\text { como uma «retomada» do uso do espaço público). } \\
\text { 3. Duelo de MC's (já mencionado). } \\
\text { 4. Projeto Cidade que Queremos (novo modelo } \\
\text { de participação política de forma colaborativa e } \\
\text { conduzida por vereadores e demais lideranças } \\
\text { políticas). }\end{array}$ & $\begin{array}{l}\text { Afirmou desconhecer iniciativas como essas } \\
\text { especificamente. }\end{array}$ \\
\hline $\begin{array}{l}\text { Experience } \\
\text { Infinity }\end{array}$ & $\begin{array}{l}\text { 1. SEED - Startups and Entrepreneurship Ecosystem } \\
\text { Development (programa de aceleração de startups, } \\
\text { financiado com recursos públicos e direcionado a } \\
\text { empreendedores que desejam criar negócios em } \\
\text { Minas Gerais. Com este perfil, é a única do Brasil). } \\
\text { 2. FiemgLab (programa de aceleração da Federação } \\
\text { das Indústrias de Minas Gerais que visa estabelecer } \\
\text { novos negócios/parcerias entre startups e indústrias } \\
\text { mineiras). } \\
\text { 3. Tecmall (é uma aceleradora de startups que } \\
\text { está inserida no Lemonade, um programa de pré- } \\
\text { aceleração de startups desenvolvido por parceria } \\
\text { público-privada e que já envolveu mais de } 200 \\
\text { startups e } 800 \text { empreendedores). } \\
\text { 4. SebraeLab (é um espaço criado pelo Serviço de } \\
\text { Apoio às Micro e Pequenas Empresas para conectar } \\
\text { pessoas e empresas dispostas a inovar) } \\
\text { 5. BeerOrCoffee (aplicativo criado por empresários } \\
\text { de Belo Horizonte cuja finalidade basicamente } \\
\text { consiste em conectar usuários cadastrados que } \\
\text { possuem interesses de negócios. Aquele que convida } \\
\text { paga a primeira bebida nos estabelecimentos } \\
\text { parceiros do App, como espaços de coworking. Está } \\
\text { disponível para Android e iOS). } \\
\text { 6. Sympla (plataforma online inovadora de gestão de } \\
\text { eventos criada por empresários de Belo Horizonte). }\end{array}$ & $\begin{array}{l}\text { Sabe de um aplicativo que está sendo } \\
\text { desenvolvido para reconhecimento de áreas } \\
\text { culturais, mas que não está no ar ainda. }\end{array}$ \\
\hline
\end{tabular}




\begin{tabular}{|c|c|c|}
\hline $\begin{array}{l}\text { (Continua) } \\
\text { Secretaria } \\
\text { de Estado } \\
\text { de Turismo } \\
\text { de Minas } \\
\text { Gerais } \\
\text { (Setur/MG) }\end{array}$ & $\begin{array}{l}\text { 1. San Pedro Valley (já mencionado). } \\
\text { 2. SEED (já mencionado). } \\
\text { 3. BH-Tec (já mencionado). } \\
\text { 4. Circuito Cultural da Praça da Liberdade (iniciativa } \\
\text { público-privada que desenvolveu um cluster de } \\
12 \text { museus/espaços culturais na referida Praça e } \\
\text { entorno). }\end{array}$ & $\begin{array}{l}\text { 1. Circuito Cultural da Praça da Liberdade (já } \\
\text { mencionado). } \\
\text { 2. Jardineira da Pampulha (da década de } \\
\text { 1950 - novo passeio turístico). } \\
\text { 3. Projeto que está sendo desenvolvido no } \\
\text { prédio Rainha da Sucata (atualmente possui } \\
\text { um centro de receptivo de turistas e, em } \\
\text { breve, será também um espaço de fomento } \\
\text { a startups, sendo que a 1.a rodada será } \\
\text { com foco em empreendimentos da área de } \\
\text { turismo). }\end{array}$ \\
\hline $\begin{array}{l}\text { Empresa } \\
\text { Municipal } \\
\text { de Turismo } \\
\text { (Belotur) }\end{array}$ & $\begin{array}{l}\text { 1. Sympla (já mencionado). } \\
\text { 2. Méliuz (é um aplicativo criado por empresários de } \\
\text { Belo Horizonte no conceito «cashbank». A estratégia } \\
\text { foi criar um programa de fidelidade na qual as } \\
\text { empresas cadastradas no App possam anunciar e } \\
\text { gerar benefícios para os usuários que consomem } \\
\text { nessas empresas). } \\
\text { 3. Fazenda Urbana BeGreen Boulevard (é a primeira } \\
\text { da América Latina. Está situada em um shopping e } \\
\text { cujo terreno há produção de hortaliças orgânicas, } \\
\text { assim como venda de produtos locais e um } \\
\text { restaurante com o conceito «farm to table»). } \\
\text { 4. BeerOrCoffee (já mencionado) } \\
\text { 5. FoodieLAC (marketplace online direcionado para o } \\
\text { turismo gastronômico na América Latina e o Caribe). } \\
\text { 6. PickMeApp (app desenvolvido em Belo Horizonte } \\
\text { que organiza e oferece caronas gratuitas para as } \\
\text { pessoas que se divertem a noite. Disponível para } \\
\text { Android e iOS). } \\
\text { 7. Pub Crawl (conceito criado no exterior, mas que } \\
\text { na capital mineira já existe: um tour por bares e } \\
\text { casas noturnas geralmente com bebida liberada). } \\
\text { 8. Experience Infinity (já mencionado) } \\
\text { 9. P7 Criativo (prédio arquitetado por Oscar } \\
\text { Niemeyer localizado no centro da cidade para ser } \\
\text { polo de inovação e referência na indústria criativa - } \\
\text { está sendo revitalizado). } \\
\text { 10. FiemgLab (já mencionado). } \\
\text { 11. SebraeLab (já mencionado). } \\
\text { 12. Minas Inova (portal online que visa disseminar } \\
\text { conteúdo sobre o ecossistema de inovação de } \\
\text { Minas Gerais. Gestores do portal atuam em Belo } \\
\text { Horizonte). } \\
\text { 13. FINIT - Feira Internacional de Negócios, } \\
\text { Inovação e Tecnologia (evento de inovação pioneiro } \\
\text { no estado de Minas Gerais e que atrai eventos } \\
\text { internacionais, como a Campus Party). }\end{array}$ & $\begin{array}{l}\text { 1. Aplicativo do Carnaval de BH (apresentou } \\
\text { aos usuários, além da programação oficial, } \\
\text { serviços e informações como: onde comer, } \\
\text { postos de saúde mais próximos, trajetos e } \\
\text { alterações no trânsito, linhas de transporte } \\
\text { público, banheiros químicos, pontos wi-fi } \\
\text { free, entre outros). } \\
\text { 2. Projeto BH (trabalha diversas ações } \\
\text { de forma criativa e integrada para se } \\
\text { gerar uma relação de pertencimento, } \\
\text { conhecimento e engajamento dos cidadãos } \\
\text { com patrimônios, história e cultura de Belo } \\
\text { Horizonte, estimulando dessa forma ações de } \\
\text { placemaking). } \\
\text { 3. Decora BH (é um projeto de sensibilização } \\
\text { dos foliões para o conhecimento, respeito } \\
\text { e valorização dos diversos patrimônios } \\
\text { da cidade. Foram realizadas intervenções } \\
\text { urbanas nos principais ícones da cidade e } \\
\text { em locais com grandes aglomerações, como } \\
\text { forma de despertar no transeunte uma nova } \\
\text { leitura e experiência dos monumentos, sua } \\
\text { relação com a cidade e a preservação do } \\
\text { patrimônio, especialmente no período do } \\
\text { Carnaval, evitando, também, depredações e } \\
\text { vandalismos). } \\
\text { 4. «ldeathon: Experiência e Geração de } \\
\text { Valor» (projeto do Sebrae em parceria com } \\
\text { a Belotur que foi criado para unir e estimular } \\
\text { o desenvolvimento de pequenos negócios } \\
\text { do setor turístico, cultural e de economia } \\
\text { criativa em Belo Horizonte. A iniciativa } \\
\text { pretende aproximar os setores de turismo, } \\
\text { cultura e economia criativa para que, juntos, } \\
\text { diversifiquem e ampliem as opções do } \\
\text { turismo de experiência). }\end{array}$ \\
\hline
\end{tabular}

Fonte: Rocco e Alvares (2017), resultados da pesquisa com base nas entrevistas.

Como pode ser observado no Quadro 1, das iniciativas inovadoras criadas e/ou desenvolvidas na cidade objeto de estudo, é possível apreender que estas perpassam diversas áreas de atuação, entre estas: (i) estímulo a inovações e ao empreendedorismo, que são fomentados por Programas 
Actas del Seminario Internacional Destinos Turísticos Inteligentes:

nuevos horizontes en la investigación y gestión del turismo

Universidad de Alicante, 26 y 27 de octubre de 2017

como o SEED, FiemgLab; Tecmall (Lemonade) e SebraeLab, além do BH-TEC, P7 Criativo, Minas Inova e FINIT; (ii) eventos de ocupação do espaço público com cunho de autoafirmação e/ou reivindicação, como é o caso do Duelo de MC's e da Praia da Estação; (iii) espaços de coworking, integrados a exemplo do Aplicativo (App) BeerOrCoffee; (iv) mudanças na forma de «fazer» política com incremento da gestão pública participativa e colaborativa, conforme o «Projeto Cidade que Queremos»; (v) novos App e/ou soluções tecnológicas, como é o caso do Sympla, Méliuz, FoodieLAC, PickMeAp, Pub Crawl e Experience Infinity; (vi) redes colaborativas e de união de startups localizadas em um bairro de Belo Horizonte, a saber, San Pedro Valley. Ainda nesse âmbito, destaca-se que a startup Experience Infinity, objeto de estudo desta pesquisa, está ligada ao San Pedro Valley e foi mencionada pelo representante da Belotur e (vii) ações inovadoras no contexto da sustentabilidade ambiental (Fazenda Urbana BeGreen Boulevard), sociocultural (Circuito Cultural da Praça da Liberdade e Ideathon: Experiência e Geração de Valor) e econômico (BH-TEC, P7 Criativo, Minas Inova e FINIT).

No que diz respeito às iniciativas inovadoras na área de turismo criadas e/ ou desenvolvidas em Belo Horizonte, vale destacar que das dez citadas, nove estão relacionadas à questão cultural e uma ao turismo de saúde. Pode-se afirmar que estas iniciativas impactam o turismo diretamente, porém, indiretamente, as demais iniciativas de aspecto geral também contribuem para a construção de uma cidade/destino inteligente. Tal como visto na literatura, nem toda cidade inteligente é um DTI, mas este se apropria dos mesmos recursos e serviços de uma cidade inteligente (Brandão; Joia \& Teles, 2016).

De acordo com os representantes das instituições pesquisadas, quando perguntados se Belo Horizonte poderia ser classificada como em estágio «inicial», "em desenvolvimento» ou "avançado» de inovação, todos contestaram que em estágio «inicial». Ainda em relação à temática, os entrevistados indicaram que para a cidade avançar em seu estágio de inovação seria necessário implementar diversas ações, tal como apresenta o Quadro 2 a seguir: 
Actas del Seminario Internacional Destinos Turísticos Inteligentes: nuevos horizontes en la investigación y gestión del turismo

Universidad de Alicante, 26 y 27 de octubre de 2017

Quadro 2: Orientações para Belo Horizonte Avançar no Estágio de Inovação

\begin{tabular}{|c|c|}
\hline INSTITUIÇÕES & OPINIÃO DOS REPRESENTANTES DAS INSTITUIÇÕES \\
\hline $\begin{array}{l}\text { Parque } \\
\text { Tecnológico de } \\
\text { Belo Horizonte } \\
\text { (BH-TEC) }\end{array}$ & $\begin{array}{l}\checkmark \text { Planejamento urbano mais consistente, considerando a região } \\
\text { metropolitana e o acesso de Belo Horizonte a outras cidades de } \\
\text { Minas e de outras cidades a Belo Horizonte também; } \\
\checkmark \text { Planejamento integrado para facilitar o acesso do cidadão a } \\
\text { serviços públicos e à mobilidade. }\end{array}$ \\
\hline Beagá Cool & $\begin{array}{l}\checkmark \text { Desenvolvimento social integrado e uma mudança na forma de } \\
\text { fazer política; } \\
\checkmark \text { Envolver a população no processo de transformação da cidade. }\end{array}$ \\
\hline $\begin{array}{l}\text { Experience } \\
\text { Infinity }\end{array}$ & $\begin{array}{l}\checkmark \text { Mais incentivos e conhecimento por meio das instituições de } \\
\text { educação; } \\
\checkmark \text { Acessibilidade urbana, sinalização adequada e tecnologia no meio } \\
\text { urbano. }\end{array}$ \\
\hline $\begin{array}{l}\text { Secretaria } \\
\text { de Estado de } \\
\text { Turismo de Minas } \\
\text { Gerais (Setur/ } \\
\text { MG) }\end{array}$ & $\begin{array}{l}\checkmark \text { Maior articulação entre as iniciativas inovadoras; } \\
\checkmark \text { Linhas de financiamento com juros baixos para estimular o } \\
\quad \text { empreendedorismo; } \\
\checkmark \text { Maior comunicação entre setor público e iniciativa privada, assim } \\
\text { como entre esses atores sociais. } \\
\checkmark \text { Identificarmos melhor os problemas enfrentados pelo cidadão e } \\
\text { identificar/divulgar as instituições capazes de gerar soluções para } \\
\text { estes problemas. }\end{array}$ \\
\hline $\begin{array}{l}\text { (Continua) } \\
\text { Empresa } \\
\text { Municipal de } \\
\text { Turismo (Belotur) }\end{array}$ & $\begin{array}{l}\checkmark \text { A inovação é um processo contínuo que não se esgota, por } \\
\text { isso é fundamental que a cidade continue buscando parcerias } \\
\text { intersetoriais e integradas em âmbitos regionais, nacionais e } \\
\text { internacionais. }\end{array}$ \\
\hline
\end{tabular}

Fonte: Rocco e Alvares (2017), resultados da pesquisa com base nas entrevistas.

De acordo com o Quadro 2, é possível inferir que as ações para que Belo Horizonte avance seu estágio de inovação estão relacionadas a planejamento urbano integrado, desenvolvimento social com transformação da cidade, incentivos no âmbito da educação, articulação entre as iniciativas inovadoras e identificação/divulgação de soluções para os problemas da cidade. A falhas de logística, mobilidade urbana e comunicação evidentes em Belo Horizonte, de acordo com a representante do BH-TEC, são aspectos a serem melhorados para que a cidade seja «mais inteligente» e, portanto, servir melhor também aquele que visita a capital mineira.

Dentre as iniciativas inovadoras citadas, o BH-TEC, embora não impacte diretamente o turismo (mas indiretamente sim), é aquela que mais integra 
Actas del Seminario Internacional Destinos Turísticos Inteligentes: nuevos horizontes en la investigación y gestión del turismo

Universidad de Alicante, 26 y 27 de octubre de 2017

os pilares inovação, governança e desenvolvimento sustentável. Do ponto de vista da inovação tem-se: o fato de ser o primeiro parque tecnológico da cidade e por estimular ambientes de inovação dentro e fora do Parque. No que se refere à governança, a própria estrutura de arranjo institucional já apresenta indícios de engajamento entre os principais stakeholders do sistema local de inovação, certamente porque a iniciativa é fruto de parceria público-privada. Finalmente, quanto ao desenvolvimento sustentável, foram levantados esses principais benefícios: 1 . dimensão econômica: tem-se a produção de bens e serviços de alto valor agregado, impactando favoravelmente na balança comercial do estado e país, 2. dimensão ambiental: busca a minimização dos impactos ambientais, a exemplo de medidas de eficiência energética e usina fotovoltaica que foi instalada recentemente no teto do prédio principal; 3 . dimensão social: melhores condições de vida para a população a partir do momento em que as empresas passam a produzir produtos com maior valor agregado. Um exemplo mencionado pela representante do próprio BH-TEC foi o de uma empresa residente no Parque que criou soluções inovadoras de prevenção e combate à dengue, epidemia que em 2016 foi a pior na cidade em relação aos últimos dez anos (Smsa, 2016) e 4. dimensão cultural: eventos de difusão do conhecimento, pautados no fortalecimento de uma cultura da inovação e empreendedorismo.

No que tange às iniciativas inovadoras que impactam o turismo diretamente, pode-se afirmar que o Circuito Cultural da Praça da Liberdade é o mais avançado em termos de integração entre inovação, governança e desenvolvimento sustentável. Tal como foi evidenciado, trata-se de uma iniciativa público-privada inovadora e que desenvolveu um cluster de 12 museus/espaços culturais na referida Praça e entorno. Do ponto de vista da sustentabilidade ambiental ainda não foram verificadas ações significativas, no entanto, pode-se afirmar que o referido Circuito contribui bastante em termos de desenvolvimento econômico, social e, sobretudo, cultural.

Por fim, quando questionados sobre quais sugestões os entrevistados dariam aos empreendedores e/ou gestores públicos que atuam na cidade, estes responderam:

«Para os gestores públicos faz sentido pensar no planejamento urbano mais integrado, no sentido de tornar Belo Horizonte um pouco mais atrativa e promover [a cidade] mais no mapa, de repente usando sim as tecnologias que estão disponíveis e soluções que existem e que até mesmo são desenvolvidas aqui, usando isso em prol dessa promoção tanto do turismo como 
Actas del Seminario Internacional Destinos Turísticos Inteligentes: nuevos horizontes en la investigación y gestión del turismo

Universidad de Alicante, 26 y 27 de octubre de 2017

da cidade de uma forma mais ampla. Eu acho que se os gestores públicos se aproximassem um pouco mais dos ambientes de inovação, entendendo como internalizar soluções que são desenvolvidas pelas empresas que estão alí, e não são poucas, são muitas coisas que existem. Eu acho que seria uma coisa para empurrar um pouco também o setor privado no sentido da cidade inteligente, de promover Belo Horizonte como um destino turístico também» (Representante do Parque Tecnológico de Belo Horizonte - BH-TEC).

«Para os empreendedores é importante eles terem clareza de quais são os seus propósitos, por que assim fica muito mais fácil criar projetos baseados em seu propósito. Dessa forma, você entende muito melhor como você vai trabalhar. É importante testar, incansavelmente, o seu modelo de negócio, e ter clareza que como é algo dinâmico, pode ser necessário efetuar mudanças. Para o poder público sugiro maior abertura e transparência» (Representante da Beagá Cool).

"Os gestores públicos com atuação na área de turismo em Belo Horizonte deveriam tentar fortalecer a atividade turística como política pública. Falta «brigar» pelo turismo. Além disso, deveria haver uma melhor comunicação entre empreendedores e gestores públicos com foco na criação de soluções de impacto. É importante não só ter ideias inovadoras e/ou desenvolver tentativas empreendedoras, mas sim realizar ações efetivas» (Representante da Secretaria Estadual de Turismo de Minas Gerais - Setur/MG).

"A sugestão é aprenderem e aplicarem mais a economia colaborativa e sustentável em seus negócios e projetos. Esse é o novo mundo, o novo mercado, a nova era» (Representante da startup Experience Infinity).

«Para os empreendedores privados sugerimos a busca de soluções criativas e a criação de redes de atuação com outros empreendedores em setores tais como gastronomia e tecnologia voltada para o setor turístico. Trabalhar em diversos níveis de network (local, nacional e internacional) será sempre um elemento primordial para o desenvolvimento de setores criativos na atualidade» (Representante da Empresa Municipal de Turismo - Belotur).

Como pôde ser verificado, as recomendações estão direcionadas para um planejamento urbano mais integrado, processo mais avançado de abertura e transparência na gestão pública, fortalecimento da atividade turística como política pública, melhoria da comunicação para se gerar mais integrações, avaliações contínuas dos modelos de negócio por parte dos empreendedores (tendo em vista a dinamicidade do mercado), busca por soluções 
Actas del Seminario Internacional Destinos Turísticos Inteligentes:

nuevos horizontes en la investigación y gestión del turismo

Universidad de Alicante, 26 y 27 de octubre de 2017

criativas, desenvolvimento de redes de atuação e economia colaborativa e sustentável.

\section{Considerações finais}

O objetivo deste artigo foi atingido, pois buscou-se analisar iniciativas inovadoras realizadas em consonância com o desenvolvimento sustentável e com estímulo à governança. Belo Horizonte, campo empírico desta investigação, ainda não pode ser considerada uma cidade inteligente e nem um destino turístico inteligente consolidado, muito embora tenha potencial para isso. Segundo revisão da literatura e respostas dos cinco representantes entrevistados, envolvidos por sua vez na esfera da gestão pública, parceria público-privada, startup e coletivo urbano, a capital mineira ainda se encontra na fase inicial de inovação. Além disso, algumas das iniciativas inovadoras levantadas junto aos entrevistados demonstram ser pioneiras inclusive no Brasil, como é o caso do programa SEED e do San Pedro Valley. Contudo, a integração/articulação para se expandir os ambientes de inovação, bem como criar condições de disseminação das soluções para os problemas da cidade ainda são insuficientes. A cidade ainda possui falhas em termos de logística, mobilidade urbana e comunicação, aspectos que são essenciais para o desenvolvimento de uma «cidade inteligente» e até mesmo um Destino Turístico Inteligente (DTI).

Com o intuito de se desenvolver o presente trabalho, propôs-se a seguinte hipótese: para que Belo Horizonte seja considerada um DTI, é necessário combinar ao mesmo tempo inovação; governança e desenvolvimento sustentável. Nesta direção, e ainda que as iniciativas sejam no momento pontuais, vale destacar o BH-TEC (com impacto indireto no turismo) e o Circuito Cultural da Praça da Liberdade (com impacto direto no turismo). É válido afirmar que um DTI se reforça com ações que atendam também os moradores da cidade, podendo gerar, assim, impactos sistêmicos, inclusive no turismo, o que tende a gerar consequentemente uma experiência positiva por parte dos visitantes.

Diante do exposto, põe-se em relevo que tornar Belo Horizonte uma "cidade inteligente» e até mesmo DTI requer ultrapassar desafios do ponto de vista da comunicação, mobilidade, transporte, saúde, segurança, tratamento dos resíduos, entre outros. As duas iniciativas mais exitosas no tocante à integração entre os três pilares estão relacionadas à parceria público-privada, que encontra terreno fértil no sistema local de inovação da 
Actas del Seminario Internacional Destinos Turísticos Inteligentes:

nuevos horizontes en la investigación y gestión del turismo

Universidad de Alicante, 26 y 27 de octubre de 2017

capital mineira. Por fim, sugere-se para publicações futuras que as iniciativas inovadoras levantadas neste trabalho possam ser mais aprofundadas e disseminadas tanto no meio acadêmico quanto nas esferas do mercado e sociedade.

\section{Referências}

Alvares, D. F.; Carneiro, D. M. R. (2014), Experiências de Economia Criativa e Práticas Inovadoras: Uma Reflexão sobre a Cidade de Brasília/DF, Brasil. In: Seminário Internacional de Innovación y Competitividad en Áreas Turísticas, 2014, Alicante. Innovación y Competitividad en Áreas Turísticas - Actas del Seminário Internacional - Bloque Temático II. Alicante: Instituto Universitário de Investigaciones Turísticas de la Universidad de Alicante, 2014. v. 2. p. 01-20.

Alvares, D. (2008), Avaliação de Planos-Processo em Áreas de Desenvolvimento Turístico. Tese de Doutorado, Universidade do Minho, Portugal.

Associação Comercial e Empresarial de Minas Gerais, AC Minas (2015), Internacionaliza $B H$ (en línea), disponible en: http://www.internacionalizabh.com.br/internacionaliza, (10/03/2017).

Arbix, G. (2007), Inovar ou inovar: a indústria brasileira entre o passado e o futuro, Editora Papagaio, São Paulo.

Bandeira, P. (1999), Participação, articulação de atores sociais e desenvolvimento regional. Texto para discussão n. 630. IPEA, Brasília, Distrito Federal.

Belo Horizonte (2014), Belo Horizonte: a perfeita junção do espaço urbano e da cidade jardim em Minas Gerais, (en línea), disponible en: http://www.belohorizonte.mg.gov.br/bh-primeira-vista/arquitetura/belo-horizonte-perfeita-juncao-do-espaco-urbano-e-da-cidade-jardim-em, (20/02/2017).

Blanco, J. (2015). Libro Blanco de los Destinos Turísticos Inteligentes - estrategias y soluciones para fomentar la innovación en el turismo digital, LID Editorial Empresarial. Madrid, Espanha.

Boff, L. (2012), Sustentabilidade: O que é - O que não é, Vozes, Petrópolis.

Bollier, D. (1998), How Smart Growth Can Stop Sprawl, Essential Books, Washington, DC.

Brandão, M.; Joia, L. A.; Teles, A. (2016), Destino turístico inteligente: um caminho para transformação, Anais do Seminário da ANPTUR - 2016. São Paulo.

Brasil, Ministério do Turismo (2013), Política e Plano Nacional do Turismo - Gestão descentralizada, territórios e instituições, (en línea), disponible en: http:// www.turismo.gov.br/sites/default/turismo/o_ministerio/publicacoes/downloads_publicacoes/Apresentaxo_Gestxo_Descentralizada.pdf, (20/02/2017). 
Actas del Seminario Internacional Destinos Turísticos Inteligentes:

nuevos horizontes en la investigación y gestión del turismo

Universidad de Alicante, 26 y 27 de octubre de 2017

Brasil, Ministério do Turismo (2012), 2011: recordes nos desembarques domésticos,

(en línea), disponible en: http://www.turismo.gov.br/turismo/noticias/todas_ noticias/20120118-1.html, (20/02/2017).

Brundtland, G. H. (Org.) (1991), Nosso futuro comum, 2.ed, Editora Fundação Getúlio Vargas, Rio de Janeiro.

Buhalis, D; Amaranggana, A. (2014) Smart Tourism Destinations. In: Z. Xiang and I. Tussyadiah (eds.), Information and Communication Technologies in Tourism. Springer International Publishing, Switzerland (en línea), disponible en: http:// s3.amazonaws.com/academia.edu.documents/36271813/ENTER14SmartTourismDestinations-libre_1.pdf?AWSAccessKeyld=AKIAIWOWYYGZ2Y53UL3A\&EXpires=1495772196\&Signature=WSy9\%2FJ9DgvN6N7JR\%2FWNYnaWQev4\%3D\&response-content-disposition=inline\%3B\%20filename\%3DSmart_Tourism_ Destinations.pdf (26/05/2017).

Caiado, A. S. C. (2011), Economia criativa, FUNDAP, São Paulo.

Castells, M. (2006), A Sociedade em Rede: do Conhecimento à Política. In: Castells, M.; Cardoso, G. (Orgs.). A Sociedade em Rede: Do Conhecimento à Acção Política, Lisboa, Imprensa Nacional - Casa da Moeda.

Clarín (2011), El consumidor «/»: inteligente inflexible, informado e impulsive, Buenos Aires, (en línea), disponible en: http://www.clarin.com/sociedad/consumidor-inteligente-inflexibleinformado-impulsivo_0_447555346.html (20/02/2017).

Cohen, B. (2012), Smart cities hub. (en línea), disponible en: http://smartcitieshub. com/ 2012/11/11/smart-cities-ranking-methodology/ (22/05/2017)

De Bes, F. T.; Kotler, P. (2011), A bíblia da inovação, Leya, São Paulo.

Federação das Indústrias do Estado do Rio de Janeiro, Firjan (2016), Mapeamento da Indústria Criativa no Brasil, Rio de Janeiro.

Fontes Filho, J.; Oliveira, S.; Leitão, M. (2009), Instâncias regionais de governança em turismo: uma análise de experiência do destino Estrada Real. In: Barbosa, L. (org.) Observatório de Inovação do turismo. Editora FGV, Rio de Janeiro.

Fundação Dom Cabral, FDC (2016), O que seria a Indústria 4.0? Boletim: fevereiro/2016 - pesquisa sobre digitalização, Belo Horizonte.

Gretzel, U.; Koo, C.; Sigala, M.; Xiang, Z. (2015), Special issue on smart tourism: convergence of information technologies, experiences, and theories. Electronic Markets, 25(3), 175-177.

IESE Business School (2016), IESE Cities in Motion Index. Center for Globalization and Strategy. Spain, University of Navarra. (en línea), disponible en: http://www. iese.edu/research/pdfs/ST-0396.pdf (12/04/2017)

IBGE. Instituto Brasileiro de Geografia e Estatística (2015). Pesquisa de Inovação PINTEC - 2014, IBGE, Rio de Janeiro. 
Actas del Seminario Internacional Destinos Turísticos Inteligentes:

nuevos horizontes en la investigación y gestión del turismo

Universidad de Alicante, 26 y 27 de octubre de 2017

Li, Y.; Hu C.; Huang, C.; Duan, L. (2017), The concept of smart tourism in the context of tourism information services, Tourism Management, Volume 58, February, Pages 293-300.

Lopez de Avila, A. (2015), Smart Destinations: XXI Century Tourism. Presented at the ENTER2015 Conference on Information and Communication Technologies in Tourism, February 4-6, 2015, Lugano, Switzerland.

Ministério da Cultura, Brasil (2011), Plano da Secretaria da Economia Criativa: políticas, diretrizes e ações (2011-2014), MinC, Brasília.

Nascimento, E. P. do (2012), Trajetória da sustentabilidade: do ambiental ao social, do social ao econômico, Estud. avançados [online], vol. 26, n. 74, pp. 51-64. (en línea), disponible en: http://www.scielo.br/scielo.php?script=sci_arttext\&pi$\mathrm{d}=$ S0103-40142012000100005 (12/12/2016).

OMT. Organização Mundial de Turismo (2016), UNWTO Tourism Highlights 2016 Edition. Madri, (en línea), disponible en: http://www.e-unwto.org/doi/ book/10.18111/9789284418145, (10.03.2017).

Organização para Cooperação Econômica e Desenvolvimento, Ocde (2005). Manual de Oslo: diretrizes para coleta e interpretação de dados sobre inovação, OCDE/ FINEP, Paris.

Putnam, D. (1996) Comunidade e democracia: a experiência da Itália moderna. Fundação Getúlio Vargas, Rio de Janeiro,

Rocco, D.M.C. (2014), Visitando o século XXI: inovações para a sustentabilidade em destinos turísticos brasileiros, Tese (Doutorado em Desenvolvimento Sustentável) - Centro de Desenvolvimento Sustentável, p. 350 f., Universidade de Brasília, Brasília.

Sachs, I. (2002), Caminhos para o desenvolvimento sustentável, Organização, Paula Yone Stroh, Garamond, Rio de Janeiro.

Sachs, I. (2004), Desenvolvimento: Includente, Sustentável, Sustentado, Garamond, Rio de Janeiro.

Schwab, K. (2017), The Fourth Industrial Revolution, Portfolio Penguin, Londres. Secretaria de Estado de Turismo de Minas Gerais, Setur (2016), Observatório do Turismo em Minas Gerais - Anuário 2017, Belo Horizonte.

Sen, A. (2010), Desenvolvimento como liberdade, Companhia das Letras, São Paulo. Serviço de Apoio às Micro e Pequenas Empresas, Sebrae (2014), A economia criativa, (en línea), disponible en: https://www.sebrae.com.br/sites/PortalSebrae/ufs/mg/sebraeaz/economia-criativa-mg,c34f22f1dfe19410VgnVCM1000003b74010aRCRD, (15/03/2017). 
Actas del Seminario Internacional Destinos Turísticos Inteligentes:

nuevos horizontes en la investigación y gestión del turismo

Universidad de Alicante, 26 y 27 de octubre de 2017

Serviço de Apoio às Micro e Pequenas Empresas, Sebrae (2016), Boletim de Inteligência, (en línea), disponible en: https://www.sebrae.com.br/Sebrae/Portal\%20 Sebrae/Anexos/BI_Tur_2016_06_Destinos\%20Tur\%C3\%ADsticos\%20Inteligentes.pdf, (15.03.2017).

Secretaria Municipal de Saúde, Smsa (2016), LIRAa - Levantamento de Índice Rápido do Aedes aegypti, (en línea), disponible en: http://www.pbh.gov.br/smsa/dengue/index.php, (15.03.2017).

SmartSantander (2017), SmartSantander, (en línea), disponible en: http://www. smartsantander.eu/, (15.03.2017).

Sociedade Mercantil Estatal para a Gestão da Inovação e das Tecnologias Turísticas, Segittur (2012), Destinos turísticos inteligentes, (en línea), disponible en: http:// www.segittur.es/es/proyectos/proyecto-detalle/Destinos-Tursticos-Inteligentes-00006/\#.WSR2y8Zv_IU, (23/05/2017).

Tidd, J., Bessant, J. (2015). Gestão da inovação, 5 ed, Bookman, Porto Alegre.

Trilha Mineira da Inovação, TMI (2017). Trilha Mineira da Inovação, (en línea), disponible en: http://www.simi.org.br/trilhamineiradainovacao, (23/05/2017).

United Nations Conference on Trade and Development, Unctad (2016), Creative economy, (en línea), disponible en: http://unctad.org/en/Pages/Home.aspx, http:// unctad.org/en/Pages/DITC/CreativeEconomy/Creative-Economy-Programme. aspx (20/02/2017).

United Nations, Department of Economic and Social Affairs, Population Division (2014), World Urbanization Prospects: The 2014 Revision.

World Bank (1992), Governance and Development, World Bank/ Washington, D.C. 